\title{
The Rhine red, the fish dead-the 1986 Schweizerhalle disaster, a retrospect and long-term impact assessment
}

\author{
Walter Giger
}

Received: 30 March 2009 /Accepted: 20 April 2009 /Published online: 29 May 2009

(C) Springer-Verlag 2009

\begin{abstract}
Background The November 1, 1986 fire at a Sandoz Ltd. storehouse at Schweizerhalle, an industrial area near Basel, Switzerland, resulted in chemical contamination of the environment. The storehouse, which was completely destroyed by the fire, contained pesticides, solvents, dyes, and various raw and intermediate materials. The majority of the approximately $1,250 \mathrm{t}$ of stored chemicals was destroyed in the fire, but large quantities were introduced into the atmosphere, into the Rhine River through runoff of the firefighting water, and into the soil and groundwater at the site. The chemicals discharged into the Rhine caused massive kills of benthic organisms and fish, particularly eels and salmonids. Public and private reaction to the fire and subsequent chemical spill was very strong. This happened only a few months after the Chernobyl accident and it destroyed the myth of immunity of Switzerland regarding such catastrophes.

Aim This article reviews the damaging events of November 1986 and aims at striking stock two decades later.

Results and discussion In the aftermath of this once-percentury accident, the aim was to obtain new knowledge for the environmental sciences and to achieve progress for water pollution control issues. The following themes are discussed: mitigation measures by the chemical industry and by the governmental authorities, activities of environ-
\end{abstract}

Responsible editor: Walter Giger

W. Giger $(\bowtie)$

Eawag, Swiss Federal Institute of Aquatic Science and Technology,

8600 Dübendorf, Switzerland

e-mail: giger@giger-research.ch

W. Giger

GRC, Giger Research Consulting,

8049 Zurich, Switzerland mental protection organizations, chemical and biological monitoring, alert organization, ecological damages, ecotoxicological effects assessment, recovery and alteration of the river biology, return of the salmon, drinking water supplies, research programs, education of environmental scientists, and visions for the future.

Conclusions The catastrophic pollution of the Rhine in November 1986 has triggered by the openly visible damages of the river biology that subsequently significant progress was made towards the prevention of such environmental catastrophes. The crucial risk reduction measures in the chemical industry, legal regulations and controls as well as chemical and biological monitoring of the river water quality were substantially improved. Politics and chemical industry have learned their lectures and have proceeded accordingly.

Recommendations A drastic acute contamination, as it has happened at Schweizerhalle in 1986, is clearly recognizable by the toxic effects, which it is causing. This can lead to mitigation activities, which are positive considering a longterm perspective. However, the less obvious effects of chronic water pollution should receive more attention as well as the ongoing alteration of the biocenosis. A high water quality must be demanded for using water from the Rhine to produce drinking water. In that context, micropollutants should also be considered and particular attention should be payed to emerging contaminants.

Perspectives The big chemical storehouse fire of $1986 \mathrm{had}$ an important impact on the transboundary cooperation and has improved the willingness for international cooperation. The fire catastrophe of Schweizerhalle has triggered many activities in particular for the Rhine River. Overall, the effects are positive on the basis of a long-term perspective. The applied whole basin approach gives an example on a global basis for other river systems, which still are more heavily polluted. 
Keywords Rhine $\cdot$ Schweizerhalle $\cdot$ Sandoz $\cdot$ Pesticides Insecticides · Organophosphates · Mercury · Fish kill · Eel · Salmon $\cdot$ Ordinance against major accidents $\cdot$ Risk

\section{Introduction}

On 1 November 1986, a major fire at a chemicals warehouse in Schweizerhalle on the Rhine above Basel led to an environmental disaster with devastating consequences, especially for the biota of the Rhine (Capel et al. 1988; Eawag 2006; Güttinger and Stumm 1992; Hurni 1988). The immediately evident effects were massive regional air pollution and severe local soil contamination. What was of farreaching, international importance, however, was the pollution of the Rhine caused by the fire. The fire-fighting water, laden with chemical pollutants, was washed into the Rhine, severely damaging the river biology. The incident subsequently prompted changes in the manufacture and storage of chemical products and led to considerably more proactive management of the risks posed by stored chemicals.

The first section of this article provides an overview of the events of 1986 and the damage that occurred in the Rhine. The environmental disaster aroused widespread attention at that time, both among the public and policy makers and among environmental scientists (Behr 2002; Capel et al. 1988; Dickman 1988; Güttinger and Stumm 1992). Then follows a discussion of how quickly and to what extent the river biology recovered, and of the consequences arising from the Sandoz accident. A number of lessons are drawn from the Schweizerhalle experience, and an assessment is made of the progress that has been achieved over the past 20 years in environmental protection in general and water pollution control in particular. These conclusions are based on reports published by environmental protection organizations in Basel and the Rhine basin, on scientific and general-readership publications, and also in part on the personal perceptions and evaluations of the author, who, in November 1986 and subsequent months, was actively involved as an Eawag scientist.

\section{Retrospect of the events in November 1986}

\subsection{Major fire at Sandoz chemicals warehouse 956 in Schweizerhalle}

During the night of Friday 31 October to Saturday 1 November 1986, a fire broke out at Sandoz warehouse 956 on the industrial site at Schweizerhalle near Basel (Switzerland). Investigations carried out by the scientific branch of the Zurich city police later showed that the fire had probably originated during the packaging of the inorganic pigment Prussian blue (iron(III) hexacyanoferrate(II),
$\mathrm{Fe}_{4}{ }^{\mathrm{III}}\left[\mathrm{Fe}^{\mathrm{II}}(\mathrm{CN})_{6}\right]_{3}$ ) (Hurni 1988). In accordance with the then-current state of packaging technology, the pigment was covered with a plastic sheet and shrink-wrapped using a blowtorch. The warehousemen did not realize that the naked flame had ignited the packaged material. Some hours later, the glowing process developed into the fateful fire (Fig. 1a). In fire tests conducted after the event, Prussian blue was found to be "readily ignitable" and to burn with a "flameless, smokeless, slowly progressing glowing". These properties were, however, also described in the relevant substance documentation. The fire was discovered shortly after midnight, and within a matter of minutes the company and public fire services were attempting to extinguish the blaze and protect the surrounding area. Despite the considerable risks, the fire fighters, around 160 in all, were selfless in their efforts, as noted by the then Basel correspondent of the Neue Zürcher Zeitung in his report: "The horrific nature of the blaze was quite staggering. Again and again, exploding drums and eruptions of fire sent sheets of flame high up into the night sky, and the firemen in protective masks had a hard time of it fighting this unleashed element, especially early on." Figure $1 \mathrm{a}$ and $\mathrm{b}$ give an impression of the situation that night.

In the early hours of the morning of 1 November 1986, at $3.40 \mathrm{Am}$, the fire had been extinguished. It would have been possible to allow the warehouse to burn down completely, while maintaining "cold walls" to protect adjacent buildings. However, as one of the substances stored in a neighboring warehouse was phosgene and this highly potent poisonous gas had to be prevented from escaping at all costs, the priority for the fire services was to put out the warehouse fire as quickly as possible (Preiswerk 2005). A very high additional risk was posed by metallic sodium stored nearby (Hurni 1988), given the large amounts of water used to fight the fire (the high temperatures prevented the use of foam). By the time the fire was extinguished, the warehouse had collapsed and the scene was one of chaotic devastation (Fig. 1c, d).

One highly unfavorable circumstance was the fact that warehouse 956 , measuring 90 by $50 \mathrm{~m}$, had originally been constructed to store machinery and was only later converted for storage of chemicals. This explains, among other things, why the building lacked adequate smoke detection and sprinkler systems and only contained one dividing wall. Stock record-keeping procedures also turned out to have serious deficiencies, and as a result the stock lists published by Sandoz after the fire were amended several times. Altogether, 1,250 t of agrochemicals and intermediates were stored in warehouse 956. A summary of the products and the most important active ingredients is given in Table 1. The main substances were phosphoric acid ester (organophosphorus) insecticides, e.g., disulfoton, thiometon, and etrimphos (Capel et al. 1988; DK-Rhein 
1986). Highly toxic mercury compounds were present as fungicides in seed dressings and were marked with the fluorescent red dye rhodamine B, which in turn was responsible for the reddening of the fire-fighting water and subsequently of the Rhine (Fig. 1e).

\subsection{Emissions and damage to the environment}

The bulk of the chemicals stored in warehouse 956 were consumed by the fire, with the prevailing temperatures also


Fig. 1 a-f Photographs of the Schweizerhalle fire in November 1986. a, b The fire at warehouse 956 on 1 November 1986. c, d Warehouse 956 after the fire. e Cooling water outflow into the Rhine-discharge causing the steel girders to melt (Fig. 1c). It was not possible to determine what combustion products were generated in the process. On the basis of the malodorous smoke, it was assumed that sulfurous compounds (mercaptans) were significant components.

\subsubsection{Air}

The population of the Basel region was rudely awakened to the disaster in the early hours of the morning. As a
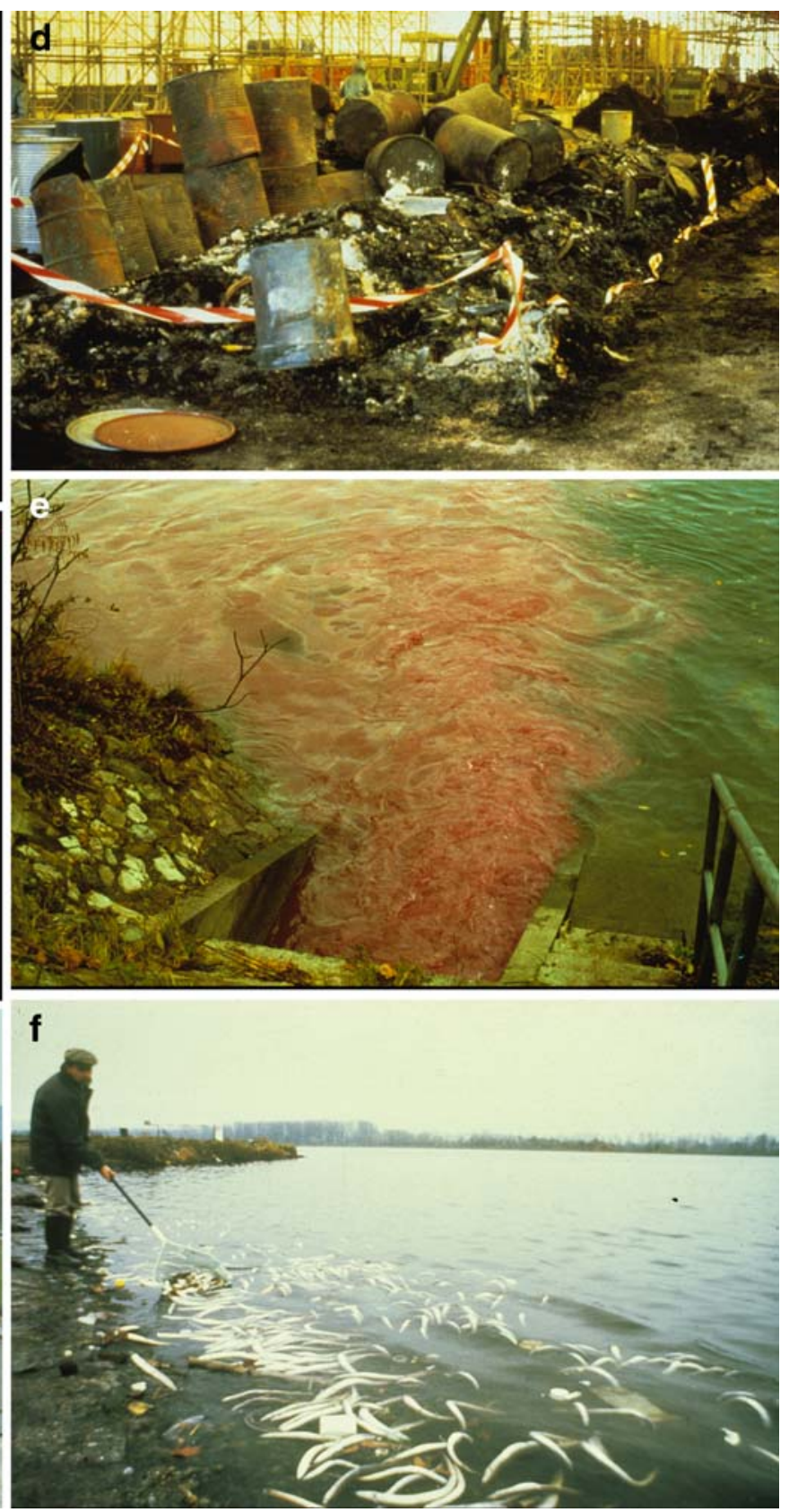

of contaminated fire-fighting water colored by the red rhodamine dye. f Fish mortality in the Rhine 
Table 1 Chemicals stored in warehouse 956 at the Sandoz plant, according to literature data (Capel et al. 1988;

DK-Rhein 1986; Hurni 1988)

\begin{tabular}{|c|c|c|c|}
\hline Products & Tonnes & Active ingredients & Tonnes \\
\hline \multirow[t]{2}{*}{ Insecticides } & \multirow[t]{2}{*}{829} & Organophosphorus insecticides & \\
\hline & & Dichlorvos & 0.1 \\
\hline \multirow[t]{2}{*}{ Rodenticides } & \multirow[t]{2}{*}{0.48} & Disulfoton & 298 \\
\hline & & Etrimphos & 67 \\
\hline \multirow[t]{2}{*}{ Herbicides } & \multirow[t]{2}{*}{72} & Fenitrothion & 9.9 \\
\hline & & Formothion & 0.3 \\
\hline \multirow[t]{2}{*}{ Fungicides } & \multirow[t]{2}{*}{40} & Parathion & 9.7 \\
\hline & & Propetamphos & 64 \\
\hline \multirow{2}{*}{$\begin{array}{l}\text { Formulation aids } \\
\text { Emulsifiers }\end{array}$} & \multirow[t]{5}{*}{91} & Quinalphos & 0.6 \\
\hline & & Thiometon & 130 \\
\hline Stabilizers & & Mercury-based fungicides & \\
\hline \multirow[t]{2}{*}{ Solvents } & & Ethoxyethylmercury hydroxide & 1.4 \\
\hline & & Phenylmercury acetate & 1.5 \\
\hline Intermediates & \multirow[t]{7}{*}{207} & Zinc-based pesticides & \\
\hline Urea & & Zineb & 0.7 \\
\hline Dodecyl benzene & & Zinc phosphide & 0.45 \\
\hline 3-Aminoacetanilide & & Other pesticides & \\
\hline Aminosulphonic acid & & Captafol & 0.16 \\
\hline \multirow[t]{2}{*}{ Monoethanolamine } & & DNOC & 65.9 \\
\hline & & Endosulfan & 2.0 \\
\hline \multirow[t]{4}{*}{ Total } & \multirow[t]{4}{*}{1,246} & Metoxuron & 11.5 \\
\hline & & Oxadixyl & 25.2 \\
\hline & & Scilliroside & 0.03 \\
\hline & & Tetradifon & 2.3 \\
\hline
\end{tabular}

foul-smelling gas cloud from the blaze was spreading across the conurbation, the authorities activated an emergency alert. In Kleinbasel and the communes of the Canton Basel-Landschaft the sirens wailed, and in Grossbasel police loudspeaker vans patrolled the streets, instructing residents to keep their doors and windows closed and to stay indoors. The situation was alarming not least because the information broadcast via local radio to residents unable to leave their homes was incomplete and contradictory, and because for some hours they did not know how dangerous the malodorous air pollution actually was. The all clear was not given until $7 \mathrm{AM}$. As the gas cloud was known-so it was claimed - not to contain any toxic substances, no lasting damage to health was to be expected.

In the early morning of 1 November 1986 in the Basel region, there was prolonged uncertainty as to whether the consequences of the Sandoz fire would be as catastrophic as those of the accidents that had occurred at Bhopal, Seveso or-in April of the same year-Chernobyl. It is not clear, to this author at least, how the risks posed by the air pollution could have been assessed with sufficient certainty.

It was only reported later that the substances stored in warehouse 956 included $2.3 \mathrm{t}$ of tetradifon, an agent used to kill mites (acaricide). Since tetradifon (4-chlorophenyl 2,4,5-trichlorophenyl sulfone) via 1,2,4-trichlorophenol is readily identifiable as a precursor for the formation of dioxins, especially the highly toxic 2,3,7,8-tetrachlorodibenzo- $p$ dioxin, soil samples and the activated carbon filters of fire fighters' protective masks were subsequently analyzed for polychlorinated dibenzodioxins and dibenzofurans in an

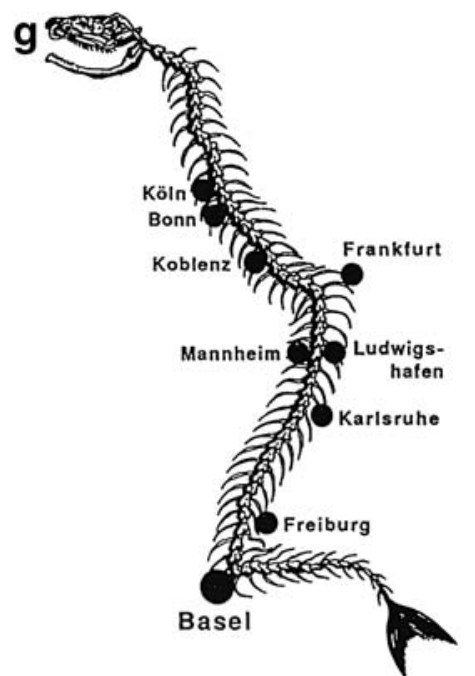

Fig. 2 Fish kill in the Rhine (cartoon from "Die Zeit", 16 November 1986) 
extended measurement program. Fortunately, no elevated concentrations were detected.

Given the rapid dynamics of air pollution, it was not possible to carry out detailed chemical analyses of air samples, such as were later performed on samples of Rhine water and sediments, groundwater, and drinking water as well as at the site of the fire and in the underlying soil. The risk of air pollution from an industrial fire remains relatively high, as was clearly demonstrated, for example, by the chemical reactor fire at a Ciba Specialty Chemicals plant in Schweizerhalle in July 2001. This fire also produced a cloud of acidic smoke and revealed deficiencies in the emergency alert system. In such cases, reliable and necessarily rapid characterization and assessment of air pollution is still hampered by relatively poor data availability.

\subsubsection{Fire site, soil, and groundwater}

Remediation of the fire site and the contaminated soil took about 6 years, with 2,700 t of semi-combusted material being disposed of. For this purpose, Sandoz had to install a shed with a special off-gas system at the storage site. About $9 \mathrm{t}$ of pesticides and $130 \mathrm{~kg}$ of organic mercury compounds had infiltrated the soil. The pollutants could be detected at depths of up to $11 \mathrm{~m}$, although the top $6 \mathrm{~m}$ of soil was the most heavily contaminated (Munz and Bachmann 1993). Among the emergency measures instituted were groundwater lowering and sealing of the contaminated soil area, together with roofing and drainage installations. In a comprehensive risk analysis, the extent of the pollution was determined and the environmental behavior of the most important contaminants was assessed. The site was then decontaminated using a complex flotation process (Munz and Bachmann 1993).

\subsubsection{Rhine pollution}

Inputs The industrial site at Schweizerhalle was equipped with a sewer system that could be sealed off in the event of an oil spill. On the night of the fire, however, the seals were not closed, but even if the system had been sealed off, the firefighting water-between 10,000 and $15,000 \mathrm{~m}^{3}$-would still have made its way into the Rhine. The red-colored runoff was mainly discharged into the Rhine via a drain designed for uncontaminated cooling water (Fig. 1e). The runoff contained large quantities of active ingredients and auxiliaries from warehouse 956, together with combustion products. While these chemicals included non-toxic adjuvants such as the red rhodamine dye, most of the substances were toxic insecticides, herbicides, and fungicides. Sandoz's initial claim that the Rhine was polluted with a harmless red dye, though certainly correct (see Fig. 1e), was unfortunately not the whole truth, as the dye in question was actually used to mark highly toxic mercury compounds. On the issue of fish mortality in the Rhine, see Fig. 1f and 2.

Figure 3 shows, for the most important pesticide substances, the quantities stored in warehouse 956 and the loads detected in the Rhine at the Village-Neuf monitoring station below Basel. It was possible to determine the latter values because weekly flow-proportional composite samples were continuously collected at Village-Neuf. This station participated in the Swiss National River Monitoring and Survey Programme (NADUF) and in the monitoring program of the International Commission for the Protection of the Rhine (ICPR). For almost all the substances, the loads measured in the Rhine were roughly proportional to the quantities that had been stored in warehouse 956 . There were three exceptionsoxadixyl, dinitro-o-cresol (DNOC), and atrazine. The observation that substantial loads of oxadixyl were also found in subsequent samples from the Rhine suggested chronic contamination, i.e., that the substance was released both before and after the Schweizerhalle fire. This hypothesis was examined in cooperation with the chemical industry, and it subsequently proved possible to eliminate the source of contamination. Atrazine had not been stored in warehouse 956, but elevated loads of this herbicide were measured in the Rhine. The special situation with regard to atrazine arose from the fact that in October 1986 an accident had occurred at Ciba-Geigy, in which wastewater contaminated with atrazine had been retained in a basin. A few days before the Sandoz fire, Ciba-Geigy began to

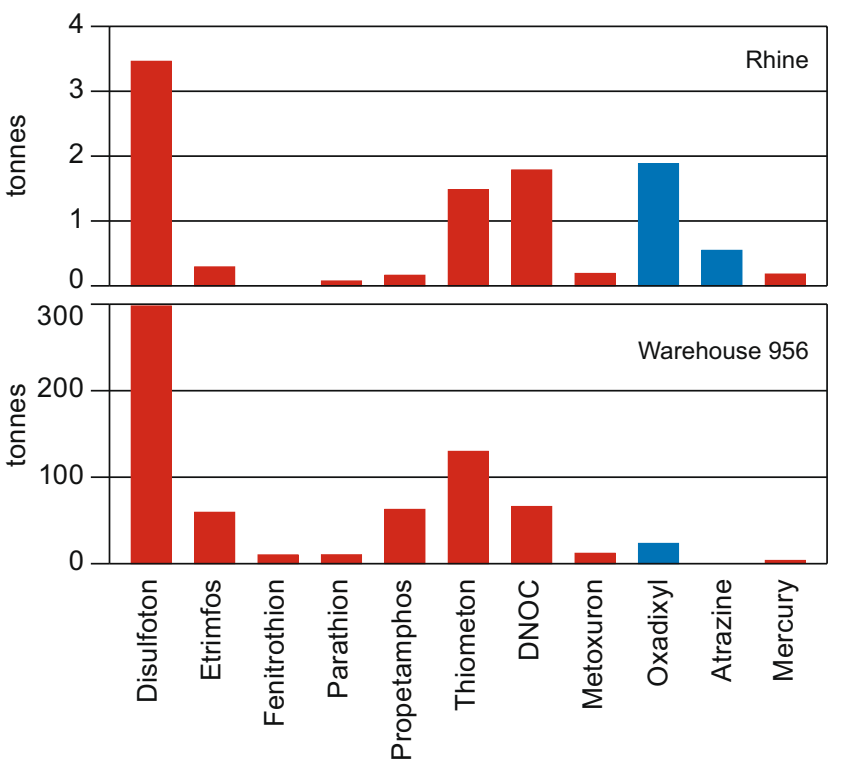

Fig. 3 Quantities of the most important active ingredients stored in Sandoz warehouse 956 and loads measured in the Rhine at VillageNeuf below Basel. These loads are based on the measurement of individual substance concentrations by capillary gas chromatography using a nitrogen-phosphorus-specific detector in a weekly flowproportional composite sample collected from 27 October to 2 November 1986. (Capel et al. 1988; DK-Rhein 1986) 
discharge this wastewater to the treatment plants, where the atrazine was only partly removed. On 31 October and the following days, approximately $0.4 \mathrm{t}$ of atrazine was released into the Rhine from the Basel municipal wastewater treatment plant and the Pro Rheno industrial wastewater treatment plant. This explains the elevated loads of atrazine measured at Village-Neuf and at the other downstream monitoring stations on the Rhine. Initially, it was suspected that Ciba-Geigy might have acted as a "free rider", taking this opportunity to dispose of the atrazine-laden wastewater. However, the sequence of events showed that this suspicion was unfounded. The company had, however, omitted to report the incident in accordance with the regulations.

The "Sandoz pollutant wave"-concurrent measurement of chemical and biological parameters and chemodynamic behavior of pollutants Figure 4 shows the values measured for two chemical and two biological parameters at Bad Honnef (Rhine km 640) in North Rhine-Westphalia. The presence of the fluorescent marker rhodamine meant that the Sandoz pollutant wave could be relatively easily and clearly recognized. The total concentration of organophosphorus insecticides measured by gas chromatography rose to a maximum of $15 \mu \mathrm{g} / \mathrm{l}$. The biological effect markers determined for the same samples (daphnia toxicity and cholinesterase inhibition) clearly indicated the insecticide impacts of the Sandoz wave. These findings represent one of the rare cases, in which measurements of chemical concentrations could be directly linked to observations of adverse biological impacts. In a certain sense, this can indeed be described as a textbook example.

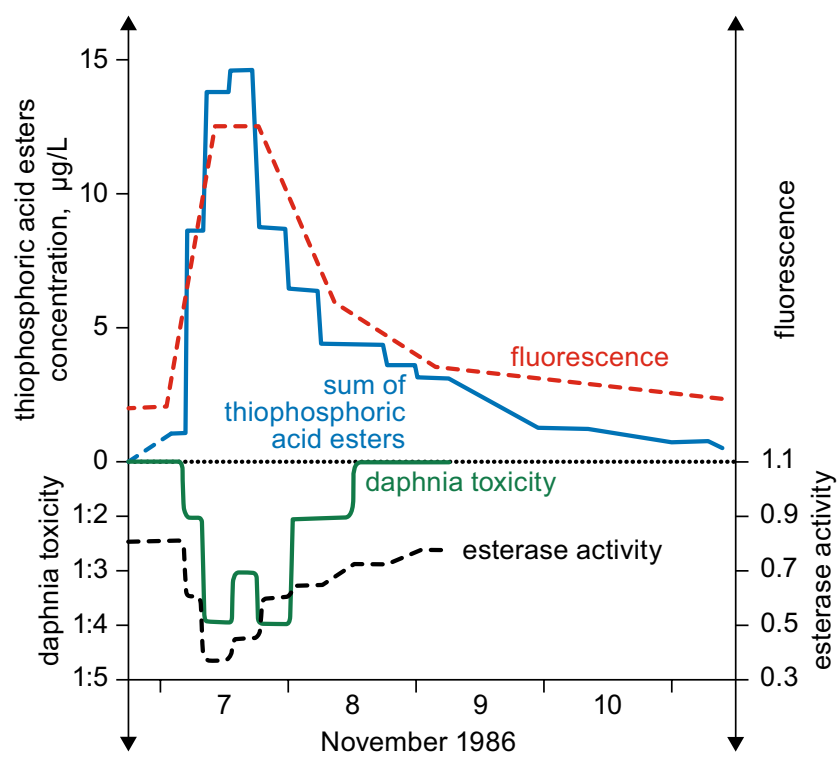

Fig. 4 Passage of the "Sandoz pollutant wave" at Bad Honnef in North Rhine-Westphalia. Reference (DK-Rhein 1986). Daphnia toxicity is expressed as the dilution factor at which Rhine water samples were still toxic to daphnia
The concentrations of disulfoton and thiometon measured at four monitoring stations along the Rhine are shown in Fig. 5, while Fig. 6 charts the disulfoton loads and includes a map of the Rhine indicating the location of the monitoring sites. On the basis of the known and in some cases field-measured substance data and the hydrological conditions in the Rhine, it was possible to model the Sandoz wave mathematically (Capel et al. 1988; Wanner et al. 1989). In Fig. 5b, the results of a model calculation performed for thiometon are plotted against the concentrations measured in the Rhine. It is evident from this comparison that the simulation of the Sandoz wave was successful. The most important factors taken into account to determine the environmental behavior were the relatively high water solubility (i.e., a weak tendency to sorb to suspended particles and sediments) and significant and quite rapid biodegradability. The latter property was responsible for the reduction in insecticide mass flows observed in the Rhine, as shown for disulfoton in Fig. 6.

\subsubsection{Damage to the Rhine ecosystem}

The German report on the Sandoz accident (DK-Rhein 1986) and subsequent publications (Güttinger and Stumm 1992) provide detailed accounts or overviews of the pollution and damage that occurred in the Rhine. In November 1986, the contamination of the Rhine resulting from the input of pollutants in fire-fighting water runoff had catastrophic effects on the river biota, including fish. Particularly striking was the eel kill, which spread from Schweizerhalle (Rhine $\mathrm{km} \mathrm{159)}$ to as far downstream as Rhine km 560 (Loreley near Koblenz).

However, other fish species were also severely affected, e.g., grayling, brown trout, pike, and pikeperch. Fish food organisms were acutely damaged in the vicinity of the accident site, while only weak effects were observed below Bad Honnef (Rhine km 640). Like fish, macroinvertebrates showed species-specific reactions to the toxic wave. Near Basel, the more sensitive Ephemeroptera and Trichoptera on the left bank of the river were affected, while Diptera and Gammaridae suffered less damage. In the Netherlands, effects of the Sandoz pollutants were noted especially in Tubificidae and Diptera larvae.

Within a few months, the recovery or recolonization of the Rhine benthos compensated for the obvious damage. That the damage was not even more extensive may be attributed to the fact that the Rhine is chronically exposed to significant chemical contamination and the channel was and remains heavily engineered; as a result, most sensitive species had already disappeared before the accident occurred.

Güttinger and Stumm sought to relate the damage observed to the ecotoxicity of the substances concerned. The eel population suffered acute toxicity at peak organo- 

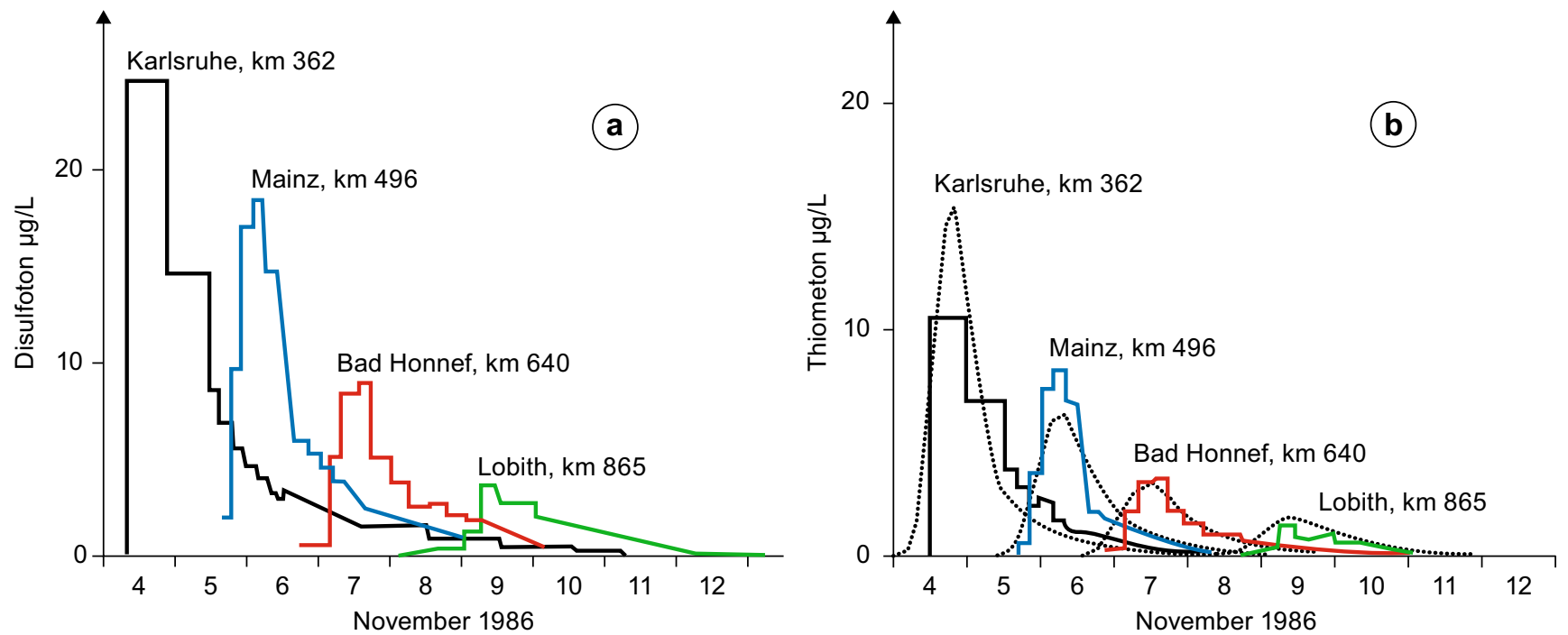

Fig. 5 Concentrations measured in the Rhine and concentration-time profiles calculated for a disulfoton and b thiometon (Capel et al. 1988; DK-Rhein 1986)

phosphate concentrations of 10-20 $\mu \mathrm{g} / \mathrm{l}$ (at Rhine $\mathrm{km} \mathrm{500-}$ 600 ). According to available toxicity data, only endosulfan is acutely toxic in this concentration range. Unfortunately, however, $\mathrm{LC}_{50}$ values for eel were not available at that time, nor were measurements carried out of the actual concentrations of endosulfan in the Rhine. Dead grayling and brown trout were found almost as far downstream as Mainz. Here, the concentration of organophosphates persisting over a period of $96 \mathrm{~h}$ was around $5 \mu \mathrm{g} / 1$, i.e., 1,000 times lower than the lethal concentration. In macroinvertebrates, adverse effects were observed at even lower concentrations. It is not possible to attribute the biological effects observed to specific concentrations of particular substances. However, it is clear that acute toxic effects occurred at significantly lower concentrations than the $\mathrm{LC}_{50}$ values would have suggested. It is necessary to consider not only synergistic effects of the substances concerned but also the fact that these pollutants added to the existing chronic contamination. In spite of dilution by tributaries, the concentrations of chronic pollutants tend to increase downstream in most cases, which may explain why Sandoz chemicals released in low concentrations still caused detrimental effects in the Netherlands. The ecosystem disturbance thus needs to be determined and evaluated in
Fig. 6 Mass flows (loads) determined for disulfoton at five monitoring stations on the Rhine (Capel et al. 1988)

relation to chronic pollution and natural variations, although the natural reference conditions are not usually available.

\subsubsection{Impacts on drinking water supplies and groundwater}

As a precautionary measure, operations at drinking water utilities along the Rhine had to be temporarily suspended over a period of more than 18 days. In retrospect, it can be said that, given the abovementioned biodegradability, the Sandoz pollutants would have been eliminated by bank filtration and thus would not have entered treated drinking water supplies. The same applies to groundwater resources fed by bank filtrate from the Rhine. Also unaffected was the groundwater body and the associated artificial recharge system in the Hardwald area adjoining Schweizerhalle. This was essentially due to the favorable hydrological situation in the aquifer.

\section{Measures taken by industry, legal regulations, and activities of environmental organizations}

The development of the Rhine protection regime triggered by the 1986 Schweizerhalle disaster had positive effects on environmental protection. A number of key measures and activities undertaken by the chemical industry, environmental organizations, and the authorities are summarized in Table 2. In addition, various lessons are listed that can be drawn from the disaster. Table 2 also includes research projects and developments in the university sector that were at least partly prompted by the Schweizerhalle accident.

After the 1986 disaster, major efforts were made to counteract the highly visible damage to the Rhine ecosystem on a long-term basis. Following the disaster, confidence in the chemical industry's ability to regulate itself was severely shaken. In Switzerland, measures taken by the authorities as a direct consequence of the fire included the introduction of the Major Accidents Ordinance (StFV) and the establishment of chemical safety inspectorates. The Swiss Major Accidents Ordinance fills the gap in regulations concerning the storage of chemicals. For example, retention basins are now legally required for any fire-fighting water that may arise. The aims of the Ordinance are to reduce hazard potentials, to prevent major accidents, and to limit impacts in the event of an accident. On the basis of a Risk Register, around 200 operations with a chemical hazard potential were identified in Switzerland and subjected to the requirements of the

Table 2 Lessons and medium- to long-term consequences of the Schweizerhalle fire

Lessons $\quad$ Industrial and institutional measures

- In principle, all chemicals can burn at sufficiently high temperatures, including those not classified as directly flammable

- When water is used for fire fighting, large amounts of contaminated runoff arise

- Analytical chemical measurements primarily detect known substances

- Hydrolytic and pyrolytic by-products are very rarely measured

- Ecotoxicological assessment of complex mixtures of pollutants is extremely difficult. Very few options are foreseeable that could contribute to the resolution of this problem for water pollution control practitioners

Regulatory measures in Switzerland and the European Union

- Swiss Major Accidents Ordinance (StFV) of 1 April 1991: operator's individual responsibility overseen by authorities, declaration of hazard potentials and risks, Risk Register, retention basins for firefighting water ("Sandoz basins"), inventory lists

- Chemical Safety, Toxicity and Environmental Inspectorate, Canton Basel-Stadt

- Safety Inspectorate, Canton Basel-Landschaft

- Chemical database, chemical accident archive

- Revision of fire prevention and fire-fighting regulations

- Revisions of EU regulations on major-accident hazards involving dangerous substances (Seveso Directive)
- Improvements in the safety of storage of chemicals and specifically agrochemicals: firewalls, segregation of substances, smoke detectors, sprinklers, installation of containment facilities for wastewater. and contaminated fire-fighting water

- Improved monitoring of cooling water streams and diversion of cooling water effluent in the event of an accident

- Expansion of network of stations on the Rhine for the monitoring of chemical water quality and biological impacts

- International Commission for the Protection of the Rhine (ICPR): Rhine Action Programme, Salmon 2000, Rhine and Salmon 2020

- International Association of Waterworks in the Rhine catchment area (IAWR): Rhine Memoranda 1973, 1986, 1995, 2003, 2008

Research projects, education

- Environmental research programs:

-Sandoz Rhine Fund

-Hewlett-Packard Rhine Basin Program

- "Man, Society Environment" project, University of Basel

- Chair in Management and the Environment, INSEAD graduate business school, Fontainebleau

- Chair in Environmental Analysis, University of Karlsruhe

- Environmental Sciences curriculum, ETH Zurich 
Ordinance. These operators are required to perform a risk estimation, develop accident scenarios, and assess the associated risks. In Cantons Basel-Stadt and BaselLandschaft, the environmental protection authorities were expanded, with the establishment of offices specifically concerned with preparedness and disaster prevention.

The activities of the International Commission for the Protection of the Rhine (ICPR 1994, 2003) were intensified. The Commission initially prepared an inventory of storage and production facilities in the Rhine basin and issued recommendations on "Prevention of Industrial Accidents and Safety of Industrial Plants". Fires are to be prevented by the establishment of protection strategies, their spread is to be controlled by engineering measures, and secondary damage is to be avoided by the retention of fire-fighting agents. All containers used for hazardous substances are to be equipped with overfill safety systems that cut off the filling operation automatically or trigger an acoustic alarm.

Plant operators are required to install sealing systems in collection troughs for leaks and accidents. Substances that may give rise to dangerous reactions (e.g., explosions) are not to be stored together. Large quantities of combustible materials are to be stored separately. Separation of streams is recommended for industrial wastewater, rainwater, and cooling water. Efforts should be made to avoid or minimize wastewater, e.g., through the use of closed systems. Hazardous substances are to be prevented from entering surface waters during trans-shipment and loading/unloading from ships, lorries, or railways to warehouses or vice versa. In-plant monitoring is required to ensure early detection of releases of hazardous substances. Emergency measures are to be precisely defined in internal alarm plans.

Over the past two decades, the chemical industry has made enormous efforts to reduce the risk of environmental pollution. These have included rigorous organization of chemicals stores and elaborate cooling water and wastewater management. At plants with hazardous substances, stores have been reduced in size or divided up and retention basins have been installed for fire-fighting water. Detailed statistics on incoming and outgoing goods mean that information is now available at any time on the quantities and precise location of substances stored.

\section{Principles for environmental research and risk evaluation-lessons of Schweizerhalle}

Güttinger and Stumm (1992) drew up eight "postulates", which remain largely valid more than 15 years later. Some of these were implemented in later developments (EU chemicals regulation REACH, Swiss chemicals legislation; precautionary principle). Extracts from three of the postu- lates, relating specifically to the 1986 Schweizerhalle disaster, are reproduced below.

I. Any acute environmental catastrophe is unique and not predictable. Therefore, large spills have to be avoided or the extent of their consequences limited. Methods of locating and evaluating risks must be found and made available, so as to prevent environmental catastrophes of an irreversible or intolerable nature. Therefore, potential emitters must be located and controlled at appropriate sites.

II. Acute harm to biocenoses can be substantially diminished by providing areas for shelter and wildlife preserves. Contrary to early fears, the biocenosis of the Rhine has recovered rather quickly, owing to the fact that in the vicinity of the accident one river bank was affected much less than the other and that tributaries and canals provided shelter, thus representing sources for recolonization by healthy animals.

III. Environmental catastrophes, as long as they are not too big and do not occur too often, are less harmful on the whole than is the chronic intoxication of the ecosystems. Anthropogenic catastrophes must not be of such an extent that a whole biocenosis could be destroyed irreversibly. If (minor) accidents do not grow into a habit, biocenoses can usually recover. However, this is not the case with permanent, chronic stress, which disturbs systematically biotopes and reduces the vitality of certain species, entailing changes in composition of biocenoses and leading to irreversible loss of genetic diversity.

Postulate no. I also included the statement that "it makes no sense to establish more and more extensive monitoring programmes, since the probability of being able to analyse relevant parameters accurately at an appropriate time and place is minimal. Besides, observing pollution neither prevents nor diminishes it." The author of this article disagrees with this statement since a different conclusion is suggested by the manifold findings of chemical monitoring stations. In the case of the Sandoz accident, for example, analysis of composite samples collected at a monitoring station downstream of the spill site provided extremely valuable results, which played an important role in the investigation of the Rhine pollution. Numerous other examples exist of cases where chemical and biological monitoring stations detected contaminations that were previously unknown or at least unreported (Diehl 2005, Rhine monitoring station from 2001). The same applies to the monitoring activities of water utilities, whose analyses control the quality of river water used as a source of drinking water. 


\section{Monitoring of chemical and biological water quality}

\subsection{Monitoring stations and programs}

Twenty years ago, Switzerland had relatively limited facilities for monitoring chemical water quality on the Rhine. Although several well-equipped sampling stations were already in operation as part of the Swiss river monitoring program NADUF and under the auspices of the International Commission for the Protection of the Rhine, these stations mainly measured conventional water parameters and a number of inorganic compounds (heavy metals, phosphates, nitrates). Specific organic pollutants were only studied sporadically (e.g., nitrilotriacetate/NTA, a detergent phosphate substitute, and nonylphenols, degradation products of nonionic surfactants). Following the Schweizerhalle disaster, the NADUF station at Village-Neuf was replaced by the international Rhine monitoring station at Weil am Rhein, which has been jointly operated by Switzerland and the state of BadenWürttemberg since 1993, with the water analyses being conducted by the chemical laboratory of the Basel-Stadt Environment and Energy Office. The Weil am Rhein monitoring station downstream of Basel now ensures a high level of analysis comparable to the services provided by the German and Dutch stations on the Middle and Lower Rhine. Some 240 individual substances are regularly monitored, and compounds not previously observed are also covered (Rhine monitoring station from 2001). To take an example: water analyses carried out at the beginning of 2006 indicated that the Rhine had been contaminated by $4.5 \mathrm{t}$ of the toxic chemical dimethylaniline. Even the company responsible for the inputs had not been previously aware of this water pollution.

The Rhine water quality station in Worms is an important link in the monitoring chain along the river. In particular, this station uses online biomonitoring methods. These systems have made it possible first to detect toxicity biologically and subsequently to identify the agents responsible with the aid of chemical analysis (Diehl 2005).

The water utilities in the Rhine basin also carry out elaborate and wide-ranging analyses, publishing their findings in their annual reports. The monitoring program is evaluated annually and, if necessary, adapted. Trend analyses are performed to determine improvements or deterioration in water quality.

The water companies' laboratories are equipped with the most advanced analytical instruments. For example, liquid chromatography directly coupled to tandem mass spectrometry is being used to develop quantitative methods for trace determination of so-called emerging contaminants. Efforts are currently focused on residues of pharmaceuticals including antibiotics and iodinated X-ray contrast media, polar pesticides, MTBE, ETBE, diglyme and triglyme, benzotriazole anticorrosive agents, and recently also perfluorinated compounds (surfactants).
In recent years, a working group at Eawag (the Swiss Federal Institute of Aquatic Science and Technology) has been studying the environmental fate of benzotriazole, a persistent compound used, for example, as a corrosion inhibitor in dishwasher detergents (Giger et al. 2006; Voutsa et al. 2006). Since benzotriazole is only partly eliminated at wastewater treatment plants, it enters receiving waters. The concentrations found in Rhine water samples collected at Weil am Rhein indicate that loads in some cases exceed $200 \mathrm{~kg}$ per week. This example shows that continuous inputs of persistent household chemicals can also lead to substantial residual concentrations in surface waters. Acute contamination, such as occurred at Schweizerhalle 20 years ago, is clearly recognizable by its detrimental effects and therefore prompted countermeasures, providing long-term benefits. However, greater attention needs to be paid to nonobvious, chronic water pollution, to which individuals contribute to varying degrees, depending on their consumption patterns.

\subsection{Rhine warning and alarm system}

If, in spite of all precautionary measures, a major accident does occur and considerable quantities of pollutants are released into the river, the Rhine international warning and alarm system is activated, alerting all the riparian states and in particular those lying downstream. When one of the seven main international warning centers between Basel and Arnhem is notified of a major accident, it alerts all the downstream centers, local authorities, and water suppliers. Water in the Rhine is continuously monitored chemically and in some cases also biologically at stations operated by the ICPR and the riparian states. The warning and alarm system is supplemented by a Rhine alarm model used by all the warning centers. This computer model can predict the passage of waves of pollution in the Rhine from Lake Constance to the North Sea. It can also forecast the passage of contaminants under different discharge conditions for major tributaries - Aare, Neckar, Main, and Mosel. Since the end of the 1980s, the number of alerts has clearly declined, from almost 60 to around 15 per year. Detailed studies of accident statistics for the Rhine indicate that the number of major industrial accidents and incidents has fallen sharply as a result of significant improvements in plant operators' preventive measures. Today, if contaminants are released into the Rhine following an accident, this is generally reported by the company responsible. In contrast, oil spills from ships are rarely traced to their source.

Overall, the findings of the Rhine monitoring stations paint an encouraging picture. There have been marked decreases in concentrations of nutrients, especially from domestic wastewater, heavy metals, and organic compounds that can be eliminated wastewater treatment plants. 
However, water temperature in the Rhine has risen by an average of $3^{\circ} \mathrm{C}$, mainly as a result of the general increase in temperatures observed in recent years. Another contributory factor is the use of river water by numerous cooling plants (nuclear power stations).

\section{Long-term biological effects-river biology: recovered, but partly altered}

As correctly predicted by experts at Eawag 20 years ago, the organisms in the dynamic river system recovered within a relatively short period. This process of regeneration was supported, for example, by (partly flood-related) flushing effects and by decolonization from the upper reaches, tributaries, and side channels. Thanks to the measures taken surprisingly rapidly by the competent authorities and industry, even the ambitious goal of the return of migratory fish species, especially the salmon, to the Rhine would appear to be attainable in the not too distant future, although the original "Salmon 2000" program has now been extended, with a new program under the heading "Rhine and Salmon 2020". The main obstacles are no longer of a chemical, but a physical nature, i.e., the disruption of river continuity by dams and hydropower turbines.

Salmon were formerly widely distributed in the Rhine. In the mid-twentieth century, the species disappeared from the river as a result of water pollution and engineering measures (dams, concrete channels). Given the improvements in water quality, the return of the salmon is now also being promoted by political efforts, with the two abovementioned international programs "Salmon 2000" and "Rhine and Salmon 2020". Initial successes are already apparent, with individual sections of the river once again passable for migratory fish. In 2004 and 2005, new salmon spawning grounds were found in two tributaries of the southern Upper Rhine.

One unfavorable development has been observed by, among others, scientists at University of Basel (Baur and Schmidlin 2006) and a working group at the Swiss Federal Office for the Environment (Rey et al. 2004). The river fauna recovered from the effects of the disaster more rapidly than expected. Many macroinvertebrate species colonized the dead parts of the Rhine from sections lying upstream of Schweizerhalle and from tributaries. At the same time, however, new, exotic species from other continents-e.g., the Caspian mud shrimp (Corophium curvispinum) and Asian clam (Corbicula spp.)-were inadvertently introduced to the Rhine by shipping. These invasive species are tolerant of changes in environmental conditions and are highly competitive, displacing native species. Benthic macroinvertebrates (crustaceans, molluscs and snails, worms) are increasingly threatened by non-native species. The researchers assume that the Schweizerhalle disaster also created free ecological niches, thereby facilitating colonization by exotic species. New species are constantly being introduced, particularly by shipping, which can successfully outcompete indigenous species, especially when these are weakened. Invasive species in the Rhine are spreading unchecked, at exponential rates. Thus, the past 10 years have seen dramatic changes in the composition of macroinvertebrate species in the Rhine at Basel. Exotic species now account for more than $90 \%$ of the biomass. Scientists are concerned about the longterm survival of specialized native aquatic fauna. The biocenosis of the Rhine is continuously striving for a new equilibrium, and these efforts are repeatedly disturbed by anthropogenic impacts.

\section{The situation 20 years later and outlook}

Looking back over two decades, the ICPR drew generally positive conclusions (see ICPR 2003 and www.iksr.org) leaving aside the immediate damage suffered by benthic organisms and fish in November 1986. The Rhine water is considerably cleaner, major accidents are less frequent, and salmon are once again migrating as far as the Upper Rhine and spawning in tributaries. It can also be seen that the Rhine is again being used for bathing. And what of the future? The ICPR now has a new vision for the Rhine: "A green stripe of floodplains edges the river, absorbs floods and is teeming with amphibian life. The diversity of fauna and flora species typical of the Rhine continues to increase. Salmon migrate upstream as far as Basel and maintain their stock without artificial stocking measures. Fish and crustaceans from the Rhine are a delicacy very much in demand." In order to realize this vision, the ICPR presented a new program at the beginning of the twenty-first century. The "Rhine 2020" program (ICPR 2005) focuses on the areas of ecosystem improvement, flood prevention and protection, and groundwater protection. In addition, monitoring and improvement of water quality is to be continued. This sustainable development program was adopted by the Conference of Rhine Ministers in January 2001. It will implement the requirements of the EU Water Framework Directive-and Swiss water policy, along similar lines-throughout the Rhine basin.

The EU Water Framework Directive of 2000 considers the river basin as an entity, calls for integrated assessment and management, establishes a list of priority substances, emphasizes the importance of biological indicators, defines good chemical and ecological status, and specifies 2015 as the deadline for achieving good status for all European waters. Experience has shown, however, that it is not easy to define good chemical and biological status for water bodies in concrete terms. In order to achieve the targets and visions, the "Rhine 2020" program includes numerous 
specific actions, with precisely quantified areas and deadlines. The actions specified are mutually complementary and reinforcing. Thus, an increase in extensive agriculture in alluvial areas promotes conservation and water quality by reducing inputs of nutrients and pollutants into ground and surface waters.

With the introduction of the Water Framework Directive, the European Union created an instrument-legally binding for member countries - whereby good status is to be achieved for all European waters by 2015. For the ICPR, ecological criteria are the current priority. In the implementation of the Water Framework Directive, a major challenge facing countries in the Rhine basin is the process of balancing the interests of water protection against those of use of the Rhine for shipping, power generation, flood protection, etc.

A different perspective is adopted by the IAWR, an association bringing together more than 120 waterworks from the six riparian states-Austria, Switzerland, Liechtenstein, France, Germany, and the Netherlands. In this area, some 30 million people rely on the Rhine, its tributaries, and the Rhine basin lakes for their drinking water supplies. About 20 million people use drinking water sourced from the Rhine.

The IAWR is committed to sustainable water management. Its aim is to protect the Rhine, its tributaries, and the prealpine lakes, so that the quality of their waters is good enough to allow drinking water to be produced using only natural methods. In its fourth Rhine Memorandum (IAWR 1973-2003), the association expresses views in stark contrast to those of the ICPR and the EU Water Framework Directive (WFD). The IAWR calls emphatically for sustainable protection of water resources, adopting revised maximum target values for concentrations of substances in water, including specific preventive values for whole groups of substances. The IAWR takes the view that, when lists of priority substances and quality objectives are specified, it is not sufficient for water quality to be assessed - as has been the practice under the WFD to date-primarily on the basis of ecotoxicological criteria, with no or insufficient consideration being given to parameters relevant to drinking water quality. Substances affecting the quality of drinking water need to be reduced to a minimum in water bodies, even if they are not currently of ecotoxicological concern.

The Rhine Memorandum 2003 (IAWR 1973-2003) includes the following ten key statements:

1. Provision of drinking water using natural purification methods. The primary aim of the Rhine water protection must be to ensure that the waterworks can provide drinking water at all times using only natural purification methods. Examples of natural methods are bank filtration and sand filtration.
2. Safety. In the interests of safety, it is essential that the quality of water used to provide drinking water should meet high demands. The requirements are based not only on the model of an intact ecosystem but also on toxicological knowledge. The IAWR member associations maintain their own monitoring system, carry out scientific studies to determine the behavior of harmful substances, and adapt their purification methods where appropriate.

3. Ecological model. Ecologically intact waters are an important prerequisite for the long-term provision of safe drinking water. It is emphasized, not least for this reason, that ecology and drinking water abstraction are mutually compatible.

4. Avoiding non-natural pollutants. Non-natural substances which cannot be broken down easily by microorganisms or which pose health concerns do not belong in the water. This applies not only to substances with proven toxicological properties but also, in the interests of safety, to all substances which do not occur naturally.

5. Avoiding point-source pollution. Point-source emissions of pollutants by industries and sewage treatment plants must be further reduced. This applies especially to small and low-volume water bodies. Undesirable substances include hormonally active substances, medicines, and biocides as well as other substances used domestically and industrially.

6. Reducing diffuse pollution. Sources of pollution such as drainage from urban and agricultural areas, seepage from landfills, and storm water overflows must be reduced. Persistent pesticides, for example, must be replaced as soon as possible by substances that can be broken down by microorganisms. The use of fertilizers or pesticides must be prohibited within a zone extending along the edge of the water.

7. Stricter hygiene standards. Lower pollution levels must also be achieved in terms of hygiene parameters. In particular, surface waters should not be contaminated by discharges of untreated wastewater containing bacteria, parasites, and viruses from combined sewer systems.

8. Limiting the effects of accidents. Accidents can lead to high levels of pollutants for a short time, thereby seriously endangering the supply of drinking water. The objective must be to maintain the best available technology for accident prevention.

9. Essential state supervision. The monitoring of water quality is a task for the authorities. As a preventive measure, the authorities must regularly test water for the presence of new substances and rapidly and fully inform the waterworks about the presence and behavior of these substances, including chemical and toxicological information. 
10. Joint responsibility. Preventive water protection requires the cooperation of everyone. This includes not only the responsible use of substances and products but also a responsibility for authorities and manufacturers to inform the public about the environmental effects of products.

In the Rhine Memorandum 2003, these requirements were given concrete form by the definition of target values for surface waters, relating to general parameters and also to inorganic and organic substances in solution.

With regard to anthropogenic non-natural substances, target values were specified, e.g., for pesticides, endocrine disruptors, pharmaceuticals, biocides, other organic halogen compounds, and synthetic complexing agents.

According to the IAWR, greater weight should be attached to the factors persistence and exposure rather than toxicity in determining the significance of substances for drinking water. This is based on the fact that a number of surface waters are contaminated with substances-usually readily soluble and at the same time extremely persistent, with high levels of exposure for humans and aquatic ecosystems-which would otherwise fall through the assessment net (e.g., complexing agents). This ranking is in line with the procedure recently adopted within the European Union for the REACH process. To reduce the concentrations of pharmaceutical substances and X-ray contrast media found in surface waters, the IAWR believes that their water-endangering potential should be taken into account in registration, as is already the case for pesticides and veterinary medicinal products.

If a disaster similar to the Schweizerhalle fire were to occur within the Rhine basin in the twenty-first century, better precautions would be in place in key areas. In particular, the retention basins now available for firefighting water would be of great value. On the other hand, the characterization and assessment of air pollution would still present major problems (cf. the Ciba fire of July 2001). Basel, the center of the Swiss chemical industry, now poses a much smaller risk, partly because operations at this location now mainly consist of research and development and the manufacture of pharmaceuticals and specialty chemicals. The production and storage of the more hazardous agrochemicals has been moved to other sites. However, no absolute guarantee can be given regarding the prevention of any major accidents. Considerable risks still exist in connection with the transport of goods by rail, road, and waterway. Twenty years on, what occurred at Schweizerhalle and on the Rhine in 1986 is more likely to take place in the chemical production centers of Eastern Europe and Asia. Today-thanks to developments in LC/MS methods - it would also essentially be possible for polar metabolites and pyrolytic products to be determined analytically. However, given the lack of appropriate reference compounds, such analyses would be of little significance. In addition, we have an extremely limited knowledge of what compounds are formed as a result of partial combustion and biodegradation in water. With regard to the assessment of ecotoxicological damage, some additional knowledge would now be available concerning species-specific effects of important chemicals, e.g., the acute toxicities of selected pesticides to eels (Ferrando et al. 1991). The problems of assessing the chronic effects of trace concentrations of individual contaminants and of mixtures of substances, however, remain to be resolved.

The recently published "Danube, Meuse and Rhine Memorandum 2008" is presented in this Special Issue of Environmental Science and Pollution Research (Wirtz 2009). This document shows that experiences made as well as pollution prevention measures and environmental quality goals developed in the Rhine-Meuse basin are now also transferred to the Danube catchment.

Overall, it may be concluded that the past two decades have seen marked improvements in water quality and the associated biological condition of the Rhine. Although important water pollution control efforts had already begun before 1986-e.g., the construction of municipal and industrial wastewater treatment plants, or regulations on the use of water-endangering chemicals - the Sandoz accident contributed substantially to the intensification of these activities on the part of industry and the authorities. The experience gained on the Rhine can serve as a rich source of instructive examples, which could usefully be applied to other aquatic ecosystems subject to anthropogenic impacts - especially also in developing and transitional countries.

Acknowledgements A German version of this article has been published earlier (Giger 2006). I am indebted to Daniel Bürgi, Herbert Güttinger, and Jan Mazacek for their very valuable comments during the preparation of that manuscript. I greatly acknowledge the excellent translation into English by Jeff Acheson.

\section{References}

Baur B, Schmidlin S (2006) Effects of invasive non-native species on the native biodiversity in the River Rhine. In: Nentwig W (ed) Biological invasions. Springer, Berlin, pp 257-273

Behr NA (2002) Die Entwicklung des Rheinschutz-Regimes unter besonderer Berücksichtigung des Sandoz-Unfalls vom 1. November 1986. brain script Nikolai A. Behr Verlag, München, p 228

Capel PD, Giger W, Reichert P, Wanner O (1988) Accidental input of pesticides into the Rhine River. Environ Sci Technol 22:992-997

Dickman S (1988) Science faces a struggle for popularity after Schweizerhalle. Nature 336:331-331 
Diehl P (2005) "Radarfalle" für Rheinverschmutzer. In: Ökowunder Rhein-20 Jahre nach Sandoz, 13. Internationale Jahrestagung des Rheinkollegs e.V., Basel, pp 27-28

DK-Rhein (1986) Deutscher Bericht zum Sandoz-Unfall mit Messprogramm

Eawag (2006) Der Rhein rot, die Fische tot-20 Jahre nach dem Sandoz-Brand. http://www.eawag.ch/media/20061101/index_EN

Ferrando MD, Sancho E, Andreu-Moliner E (1991) Comparative acute toxicities of selected pesticides to Anguilla anguilla. J Env Sci Health B 26:491-498

Giger W (2006) Der Rhein rot, die Fische tot. Brandkatastrophe in Schweizerhalle 1986-Rückblick und Bilanz. Umweltwiss Schadst Forsch 19. Sonderausgabe 1:11-23

Giger W, Schaffner C, Kohler HPE (2006) Benzotriazole and tolyltriazole as aquatic contaminants. 1. Input and occurrence in rivers and lakes. Environ Sci Technol 40:7186-7192

Güttinger H, Stumm W (1992) Ecotoxicology - an analysis of the Rhine pollution caused by the Sandoz chemical accident, 1986. Interdisciplinary Sci Rev 17:127-136

Hurni B (1988) The Sandoz accident. In: Angeletti G, Bjørseth A (eds) Organic micropollutants in the aquatic environment. Reidel, Dordrecht

IAWR (1973-2003) Rhine Memorandum 1973, 1986, 1995, 2003. International Association of Waterworks in the Rhine catchment area

ICPR (1994) Salmon 2000. International Commission for the Protection of the Rhine
ICPR (2003) Upstream - Outcome of the Rhine Action Programme. International Commission for the Protection of the Rhine

ICPR (2005) Rhine and Salmon 2020-Programme on sustainable development. Balance 2000-2005. International Commission for the Protection of the Rhine. www.iksr.org

Munz C, Bachmann A (1993) Dokumentation einer umweltgerechten Bodensanierung. Vierter internationaler KfK/TNO-Kongress über Altlasten, Berlin

Preiswerk TE (2005) Schweizerhalle nach 20 Jahren. In: Ökowunder Rhein-20 Jahre nach Sandoz, 13. Internationale Jahrestagung des Rheinkollegs e.V., Basel, pp 9-11

Rey P, Ortlepp J, Küry D (2004) Wirbellose Neozoen im Hochrhein. Ausbreitung und ökologische bedeutung., Bundesamt für Umwelt, Bern

Rhine monitoring station (from 2001) Berichte der Rheinüberwachungsstation in Weil am Rhein, http://www.aue.bs.ch/ fachbereiche/gewaesser/rheinberichte/analysen-und-ergebnisse.htm

Voutsa D, Hartmann P, Schaffner C, Giger W (2006) Benzotriazoles, alkylphenols and bisphenol $\mathrm{A}$ in municipal wastewaters and in the Glatt River, Switzerland. Environ Sci Poll Res 13:333-341

Wanner O, Egli T, Fleischmann T, Lanz K, Reichert P, Schwarzenbach RP (1989) Behavior of the insecticides disulfoton and thiometon in the Rhine river - a chemodynamic study. Environ Sci Technol 23:1232-1242

Wirtz F (2009) Danube, Meuse and Rhine MEMORANDUM 2008. Environ Sci Poll Res 16: this issue. doi: 10.1007/s11356-009-0127-3 